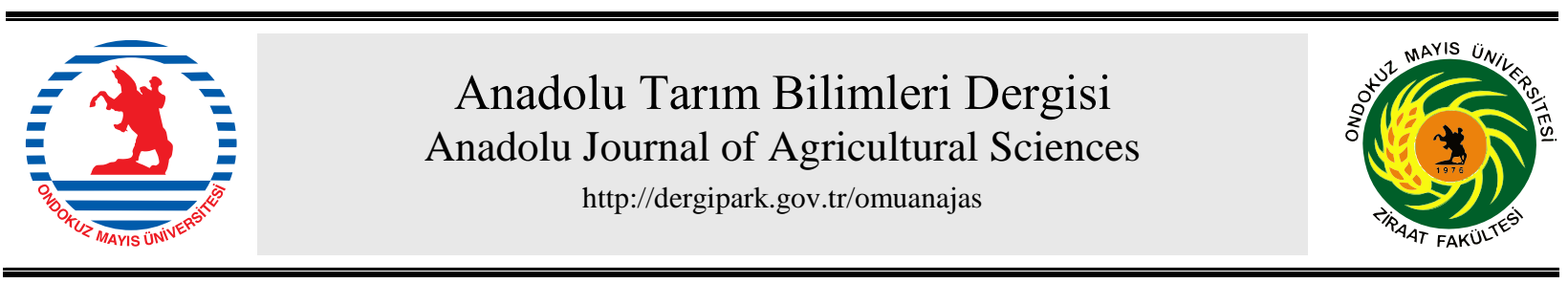

\title{
Araştırma/Research
}

Anadolu Tarım Bilim. Derg./Anadolu J Agr Sci, 36 (2021) ISSN: 1308-8750 (Print) 1308-8769 (Online) doi: 10.7161/omuanajas.908576

\section{Konya Kapalı Havzası Uzun Dönem Bitki Örtüsü İndeksi Verilerinin İzlenmesi ve Eğilim Analizi}

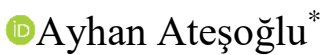 \\ ${ }^{a}$ Bartın Üniversitesi, Orman Fakültesi, Orman Mühendisliği Bölümü, Bartın, Türkiye
}

*Sorumlu yazar/corresponding author: aatesoglu@bartin.edu.tr

Geliş/Received 02/04/2021 Kabul/Accepted 24/05/2021

\begin{abstract}
ÖZET
$\mathrm{Bu}$ makale, Konya Kapalı Havzası (KKH) arazi örtü/kullanım sınıfları belirlenmesi, vejetasyon bazlı arazi izleme ve değerlendirme çalışmalarını kapsamaktadır. Bitki örtüsünün biyosfer için çok önemli bir işlevi olduğu, varlığı noktasında izlenmesi gerekli bir kriter olduğu bilinmektedir. Çalışmada, yöntem olarak ilk kez Birleşmiş Milletler Gıda ve Tarım Örgütü (FAO) tarafindan kullanılan çok amaçlı arazi izleme ve değerlendirme programı olan Collect Earth (CE) yöntemi kullanılmıştır. Uzaktan algılama ve Coğrafi bilgi sistemleri entegre sistem üzerine kurulu CE, Google Earth aracıllğı ile veri toplamayı sağlayan bir araçtır. Kullanıcılar Google Earth, Bing Maps ve Google Earth Engine ile birlikte yüksek çözünürlüklü uydu görüntü verilerini farklı amaçlara yönelik (arazi kullanımı, arazi kullanım değişimi, tarımsal arazilerin izlenmesi, arazi bozulumu ve iyileşmesi vb.) analiz için kullanabilirler. Bu çalışmada, KKH'nın normalleştirilmiş fark bitki indeksi NDVI değerleri kullanılarak 2000-2018 yılları arasındaki arazi bozulumu/çölleşme ve iyileşme/yeşillenme eğilim analizleri gerçekleştirilmiştir. Çalışma sonucunda, havza alanında 2000-2018 yılları arasında toplam 88916 ha alanda iyileşme, 10570 hektar alanda arazi bozulumu tespit edilmiştir. İyileşmiş alanlarının \%85'i tarım alanları içerisinde olduğu tespit edilmiştir. İyileşme alanlarının en çok 2009-2011 yılları arasında gerçekleștiği de belirlenmiştir. Elde edilen sonuçlar havzanın arazi örtü/kullanım sınıfları nezdinde tartışıımıştır. CE'nin kullanıcı dostu olması, sorunsuz öğrenme eğrisi, hızlı, doğru ve uygun maliyetli değerlendirmeler yapması ve belirli veri toplama ihtiyaçları ve metodolojileri için oldukça özelleştirilebilir olması nedeniyle etkili bir yöntem olduğu da vurgulanmıştır.
\end{abstract}

\section{Monitoring and Trend Analysis of Long-Term Vegetation Index Data in Konya Closed Basin}

\section{ABSTRACT}

This article covers the determination of land cover/use classes in Konya Closed Basin (KKH), vegetationbased land monitoring and assessment studies. It is known that vegetation has a very important function for the biosphere and is a criterion that must be followed. In the study, the Collect Earth (CE) is a tool, which a multi-purpose monitoring, used for the first time by the United Nations Food and Agriculture Organization (FAO). Collect Earth is a tool that enables data collection through Google Earth. In conjunction with Google Earth, Bing Maps and Google Earth Engine, users can analyze high and very high-resolution satellite imagery for a wide variety of purposes (Land Use, Land Use Change, Monitoring agricultural land areas, land degredation etc.). In this study, land degradation/desertification and improvement/greening trend analyzes between 2000-2018 were performed using normalized difference plant index NDVI values of KKH. Because of the study, improvement in a total area of 88916 ha and land degradation in an area of 10570 hectares were detected between 2000-2018 in the basin area. It has been determined that $85 \%$ of the improved areas are in the cropland. It has also been determined that the areas of improvement mostly occurred between 2009-2011. The results obtained were discussed in terms

Anahtar Sözcükler: Konya Kapalı Havzası Arazi kullanım sinifları NDVI analizi Collect Earth 
of land cover/use classes of the basin. Evaluations were made on the causes of greening, especially for cropland. It has been emphasized that it is an effective method due to its user friendliness, smooth learning curve, performing fast, accurate and cost-effective assessments and be highly customizable for the specific data collection needs and methodologies.

\section{Giriş}

Bitki örtüsü, bir bölgenin bitki yaşamı için kullanılan en genel terimdir. Bitkiler tarafından sağlanan toprak örtüsünü ifade eder ve biyosferin en çok varlığını oluşturan unsurlardan biridir. Dolayısı ile bitki örtüsü, Dünya'nın yüzey sisteminin tanımlayan önemli bir biyofiziksel parametredir (Jones ve Vaughan, 2010). Bitki örtüsü, biyosfer için birkaç kritik işleve sahiptir. İlk olarak, biyojeokimyasal döngünün akışını sağlar. Bu durum iklim koşulları içinde büyük önem taşımaktadır. İkinci olarak, bitki örtüsü başta üretkenlik olmak üzere toprak özelliklerini güçlü bir şekilde etkiler. Yaban hayatı ve enerji kaynağ1 olarak da büyün öneme sahiptir. (Bahre, 1991).

Vejetasyon takibi yapılarak çölleşme ve arazi bozulması veya tam tersi yeşillenme ve iyileşme tespiti yapmak mümkündür (Bai et. al., 2008; Bai et. al., 2010; Yengoh et. asl., 2015). Bu konuda, kısıtlayıc1 unsurlardan biri küresel ya da ülkesel ölçekte vejetasyon takibi yapmayı sağlayacak veri ve yöntem gereksinimleridir (Veron et. al., 2006). Bu bağlamda, uzaktan algılama (UA) verileri ve analiz aracı olan Coğrafi bilgi sistemleri (CBS) disiplinleri öne çıkmaktadır. Özellikle arazi izleme ve değerlendirme çalışmalarında iki disiplinin birlikte kullanımı, araziye yönelik hassas ve doğru bilgilere ulaşma imkanı tanımaktadır (Sluiter, 2005; Liping et. asl., 2018; İslam et. al., 2021). Birçok vejetasyona yönelik arazi çalışmalarında özellikle orta çözünürlüklü uydu görüntü verileri için bitki örtüsü indeksleri kullanılmaktadır (Bannari et. al., 1195; Yagci et. al., 2011; Lu et. al., 2015; Zhao et. al., 2020). Bitki indeksleri içinde Normalleştirilmiş fark bitki indeksi (NDVI) en çok kullanılan indeks görüntülerden biridir Özellikle uydu bazlı görüntülerden vejetasyona ilişkin değerlendirmelerde sıklıkla kullanılmaktadır(Wallece ve Campbell, 1990; Sobrino ve Julien, 2011). Özellikle de tarım ve orman alanlarında yoğun olarak kullanıldığı bilinmektedir (Zhu et. al., 2021; Ivanova et. al., 2021). NDVI fotosentetik olarak aktif biyokütlenin basit bir göstergesi ve bitki sağlı̆̆ının bir göstergesidir. En genel manada, NDVI bitki örtüsünü diğer arazi örtüsü sınıflarından ayırmaya ve arazinin genel durumunu belirlemeye yardımcı olur. NDVI yakın kızılötesi bant ile kırmızı bant farkının, toplamına oranı şeklinde hesaplanır. Çoğu durumda 1 ile -1 arasında bir değişken olarak hesaplanmaktadır. Elde edilen sonuç en genel manada, 0.2-0.4 arası ise seyrek, 0.4-0.6 ise orta yoğunlukta, 0.6 dan büyük bir değerde ise yoğun bitki örtüsü olduğu kabul edilir. Aralık değerleri farklı amaca yönelik çalışmalar için değişkenlik da gösterebilir. NDVI sonuçları vejetasyonun durumunu, sağlığını ve canlılığına dair bilgiler vermektedir. Bu yönü ile büyümenin göstergesi verimlilik ve biyokütle ile güçlü bir korelasyona sahiptir (URL 1). Tüm bunlara ek olarak, NDVI zaman serileri kullanılarak iyileşme/yeşillenme ve bozulma/çölleşme eğilimlerine ilişkin küresel ve bölgesel çalışmalar yapılmaktadır (Jong et al., 2011). Farklı yöntem ve platformalar aracılığı ile farklı çözünürlükteki uydu görüntü verilerinin NDVI zaman setleri üzerinden vejetasyona ilişkin eğilim sonuçları elde edilebilmektedir (Wessels et. al., 2007; Wessels et. al., 2012; Guo et. el., 2020).

$\mathrm{Bu}$ çalışmada, ilk olarak Food ve Agriculture Organization (FAO) tarafından geliştirilen ve kullanılan, Open Foris şirketi bünyesindeki açık kaynak kodlu bir yazılım olan Collect Earth (CE) kullanılmıştır. CE java alt yapısını kullanarak Google Earth, Bing Maps, Yandex Maps gibi görüntü sağlayıcılarına ve Google Earth Engine (GEE) açık veri kaynaklarına erişim sağlayabilmektedir. Bu bağlamda, $\mathrm{CE}$ genel olarak arazi örtü/kullanım çalışmalarında kullanılmaktadır (Bey ve ark., 2016; Martin-Ortega ve ark., 2017; Ateşoğlu ve ark., 2019; Saah ve ark., 2019; Tzamtzis ve ark., 2019; Kahdka ve ark., 2020). CE uzman olan yada olmayan kullanıcıların, çok yüksek geometrik çözünürlüğe sahip görüntüler (Google earth, bing maps ve yandex maps) kullanarak ve uydu görüntü bazlı uzun zaman grafik veri ve görüntü serilerinden de (GEE ve GEE Code Editor) faydalanarak veri toplamaya olanak sunmaktadır (Bey ve ark., 2016; ve ark., Gorelick 2017). Çalışmada, Konya Kapalı Havzasının (KKH) arazi örtü/kullanım sınıfları belirlenmesine yönelik olarak, 2000-2018 yılları arasındaki, NDVI verileri yardımı ile (Şekil 1) arazi bozulum/çölleşme ve iyileşme/yeşillenme eğilim analizleri gerçekleştirilmiş ve haritalanmıştır. 

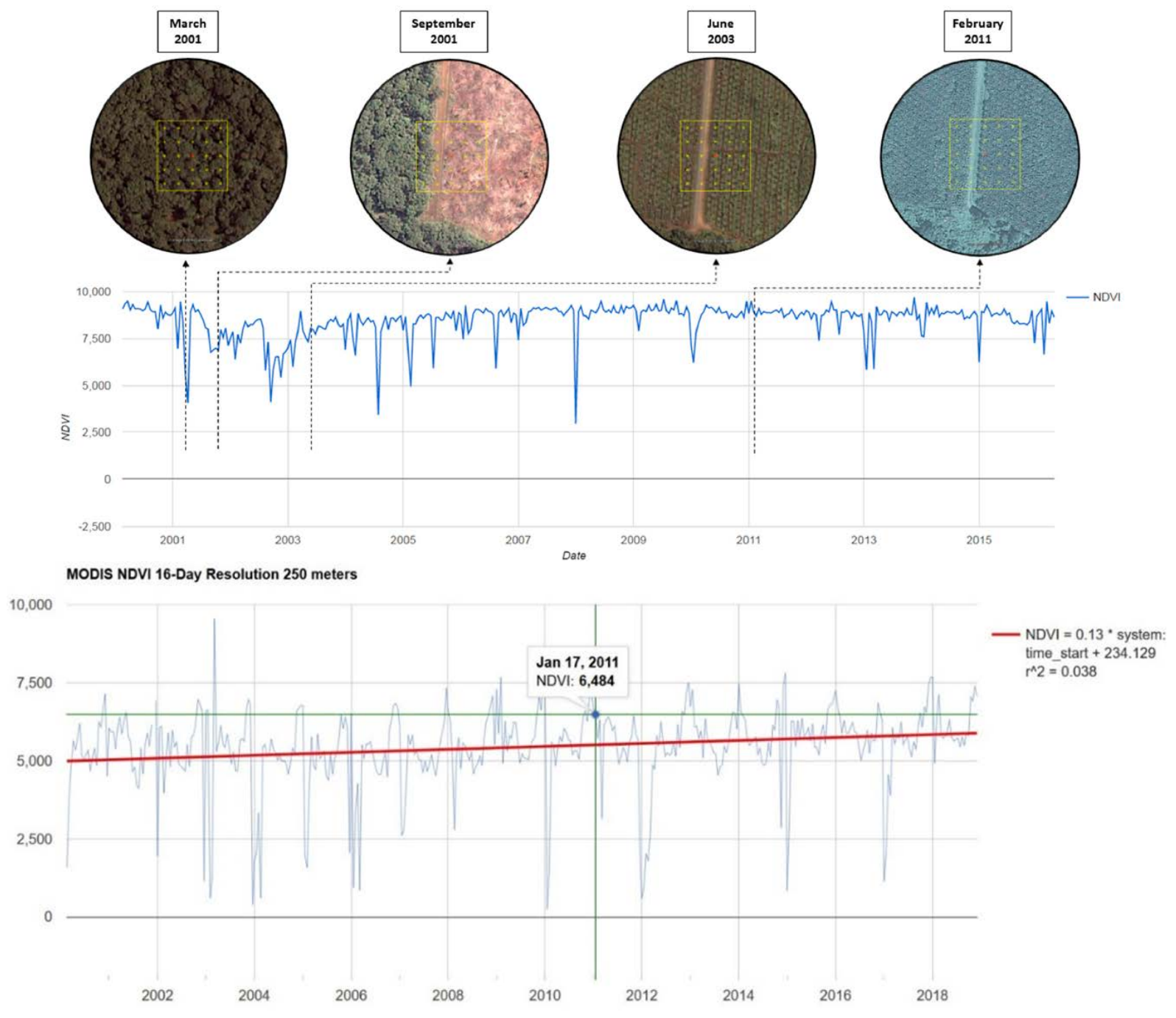

Date

Şekil 1. MODIS 16 günlük NDVI grafik verisi üzerinden plota ilişkin arazi kullanım değişikliği ilişkisi (Bey ve ark., 2016) (üstte); NDVI grafik verisi üzerinden eğilim analizi örneği (altta).

Figure 1. Land use change relationship regarding the plot based on MODIS 16-day NDVI graph data (Bey ve ark., 2016) (top); Example of trend analysis using NDVI chart data

\section{Materyal ve Yöntem}

\section{1 Çalışma alanı}

Çalışma alanı olarak seçilen Konya Kapalı Havzası (Şekil 2), Türkiye'nin yaklaşık \% 7'sini (49805.32 km²) bir alana sahiptir (Şekil 1). Havzada \%45'i kırsalda, \%55'i kentlerde yaşamak üzere yaklaşık 3 milyon insan yaşamaktadır (Atesoglu et.al., 2019). Havza sınırları içerisinde Konya, Niğde, Isparta, Aksaray, Ankara, Karaman ve Nevşehir illerini bağlı bölgeler bulunmaktadır. Havzaya alansal olarak hakim il Konya ilidir. KKH yüksek bir plato alanıdır. Düz ve düze yakın bir topografyaya sahip havza ortalama $1000 \mathrm{~m}$ yüksekliktedir. Güneyinde Toroslar, batısında Gavur Dağları, doğusunda Melendiz Dağları bulunmaktadır. Yağışların az olduğu havzada mevcut akarsuların çoğu yaz periyodunda kurumaktadır. Havzanın orta ve kuzey kesimleri oldukça kurak geçen karasal iklim rejimindedir. Hatta Karapınar ve çevresinde çöl iklim özellikleri gözlenmektedir. Bölgenin göl bazında ana aktörü ise Tuz Gölüdür. Tuz gölü ve yakın çevresi KKH'nın alt havzasıdır (Tübitak, 2010). 


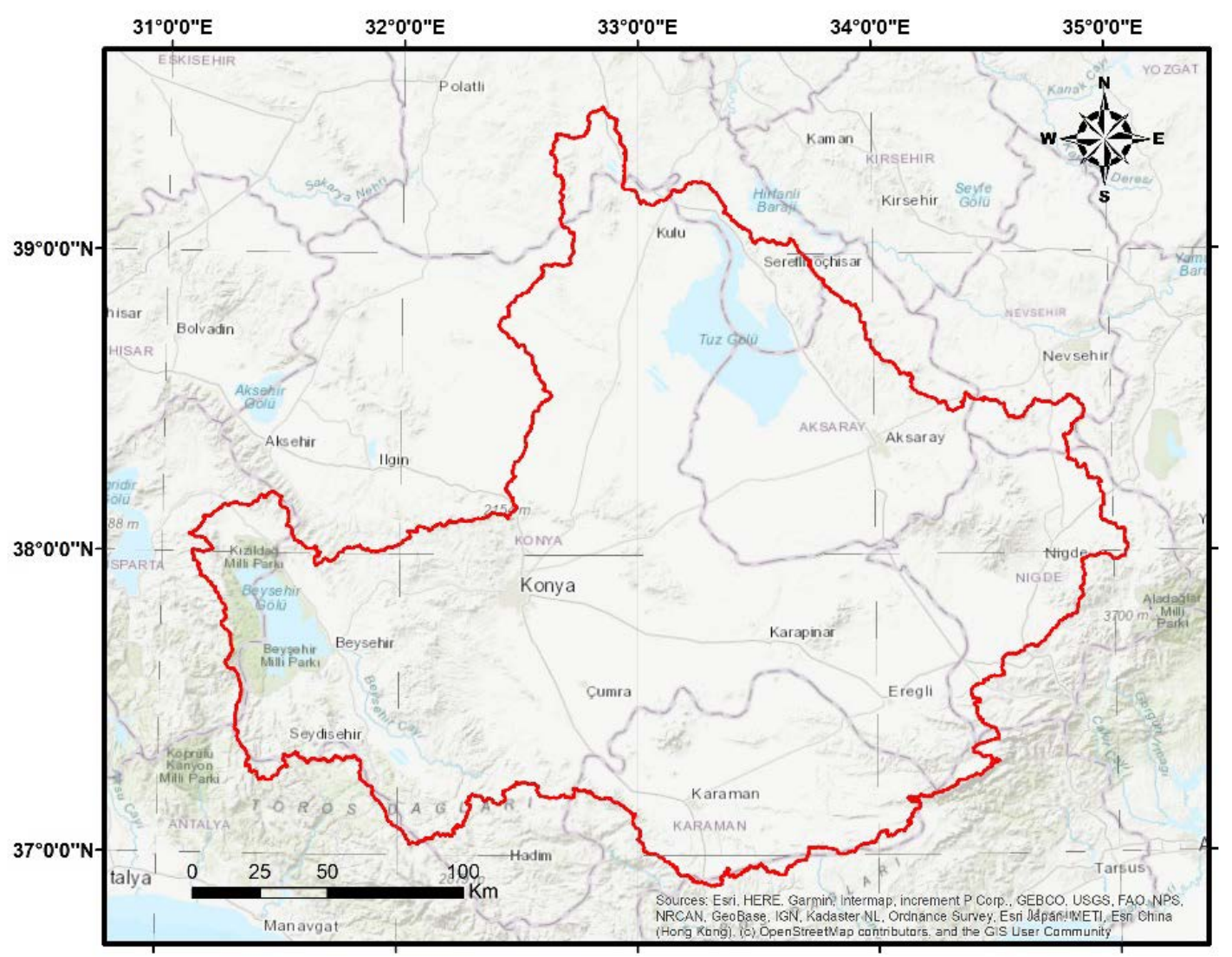

Şekil 2. Konya Kapalı Havzası

Figure 2. Konya Closed Basin

\subsection{Yöntem}

Çalışma alanı tanımlandıktan sonra, arazi izleme ve değerlendirme için uzaktan algılama araçlarından biri olan Collect Earth (CE) tercih edilmiştir. CE, FAO tarafından geliştirilmiş ve ilk olarak küresel orman envanteri ve kurak alanlarının değerlendirilmesi projesi kapsamında kullanılmıştır. CE arazi örtü/kullanım sınıflarının izleme ve değerlendirilmesi için yüksek çözünürlüklü uydu görüntü verilerden elde edilen görsel analizi ve genel olarak orta çözünürlüklü uydu görüntü verileri üzerinden elde edilmiş grafik verilerin analizini bir arada değerlendirme firsatı sunar. Bu bağlamda birçok arazi izleme ve değerlendirme platformlarından farklı bir çalışma prensibine sahiptir. Görsel bir yorumlama yapabilmek amaçlı, objeye ve arazi sınıflarına ilişkin rakamsal veri temini için Google Earth, Bing Maps ve Yandex Maps gibi tüksek çözünürlüklü veriye ulaşım imkanı sağlamaktadır. Aynı alanlara ilişkin genellikle orta çözünürlüklü uydu görüntü veri serileri (Modis, Landsat, Sentinel vb.) üzerinden indeks görüntülerin (NDVI, NDWI, EVI vb.) uzun yıllar grafik verilerini sunarak, kullanıcıya ilgili indeks verileri üzerinden yorumlama ve anlamlandırma imkanı tanımaktadır. Son olarak veri tabanına işlenen tüm verilerin istatistik olarak değerlendirilebileceği bir istatistik yazılım (SAIKU) imkanı sağlamaktadır (Şekil 3). CE arazi çalışmaları ile tamamlanması mümkün olmayan, araziye yönelik küresel, ülkesel ve bölgesel veri toplamak için uygun bir metodolojiye sahiptir. Bey ve ark. 2016 yılında CE’ye ilişkin tüm modülleri içeren bir makale yayınlamış ve yönteme ilişkin tüm detayları paylaşmışlardır. 


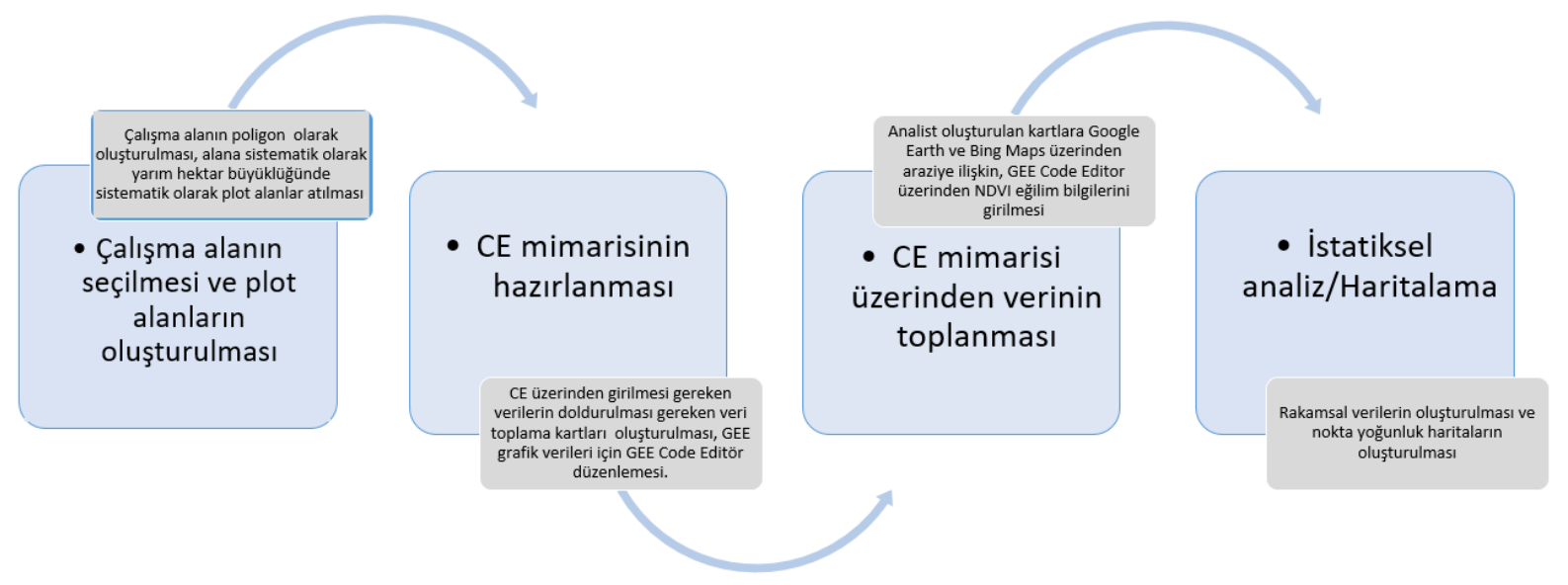

Şekil 3. İş akış şeması

Figure 3. Flow chart templates

Çalışma kapsamında KKH'na toplam yarım hektar büyüklüğünde 8010 plot atılmış ve tüm değerlendirmeler bu plotlar üzerinde gerçekleştirilmiştir. Her bir plot aralığı Doğu-Batı yönünde aralıkları yaklaşık 3 km, Kuzey-Güney yönünde aralıkları yaklaşık 3,8 km'dir. Tüm plotların CE üzerinden değerlendirilmesi için birkaç ön işlemin yapılması gereklidir. Plot alanların sayısı, plotların boyutu ve plota ilişkin değerlendirmelerin yapılması için gerekli önyüzlerin hazırlanması "Collect" yazılımı ile gerçekleştirilmiştir.. Bu çalışmada plot alanı yarım hektar olarak belirlenmiş ve her biri plot için alanı $4 \mathrm{~m}^{2}$ olan toplam 49 araştırma karesi kullanılmıştır (Şekil 4). Bu şekilde özellikle arazi kullanım sınıfları yüzde hesabı hesaplanabilmiştir.

İkinci aşamada Collect yazılımı aracılığı ile arazi izleme ve değerlendirme kartı oluşturulmuştur. Kart üç bölümlü olarak oluşturulmuş olup her bölüm kendi içerisinde bir amaca yöneliktir. İlk bölüm, "Arazi verileri”" başlığı altında verilmiş ve uydu görüntü verisi yıll, vejetasyon kaplama örtüsü, riperian gibi, yol gibi vejetasyona sahip uzunluklar, alt yapı kaplama oranları ve su yapılarına ait kaplam oranlarının girildiği alanları kapsamaktadır. İkinci bölüm ise "CEM" olarak adlandırılan NDVI ortalama değerin girildiği, çölleşme/bozulum ve yeşillenme/iyileşme eğilimlerinin belirlendiği, NDVI değişimi var ise değişim yılı bilgilerinin doldurulduğu ve buna neden olan başlıca etmenlerin sıralandığı bölümleri kapsamaktadır. Son bölüm ise, "FRA/IPCC" olarak adlandırılan Birleşmiş Milletler Gıda ve Tarım Örgütü (FAO) ve Hükümetler Arası İklim Paneli (IPCC) sınıflarına göre arazi örtü/kullanım sınıflarının ve bunlara ait alt kullanım sınıflarının (FAO/FRA 2015; IPCC, 2003) belirlendiği, arazi kullanım değişiminin Google Earth zaman serisi ile tespit edilerek arazi kullanım değişiminin yılı ve değişim sınıfları bilgilerinin doldurulduğu bölümleri kapsamaktadır (Şekil 5).

$\mathrm{Bu}$ çalışmanın arazi verisine ilişkin sonuçları Ateşoğlu ve ark., 2019 'da yaptığı çalışmada verilmiştir. Bu çalışmada ise IPCC arazi sınıflarına ilişkin sonuçlar üzerinden NDVI verileri üzerinden vejetasyonun izlenmesi ve eğilim analizi sonuçları paylaşılmıştır.

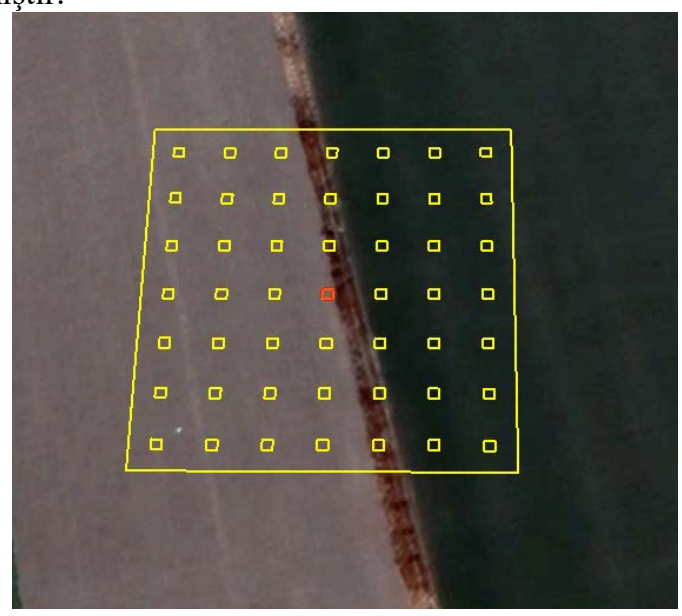

Şekil 4. Görsel yorumlama ve analiz için kullanılan yaklaşık 0.5 hektar büyüklüğündeki plot alan Figure 4. Approximately 0,5 hectares of plot area, used for visual interpretation and analysis 

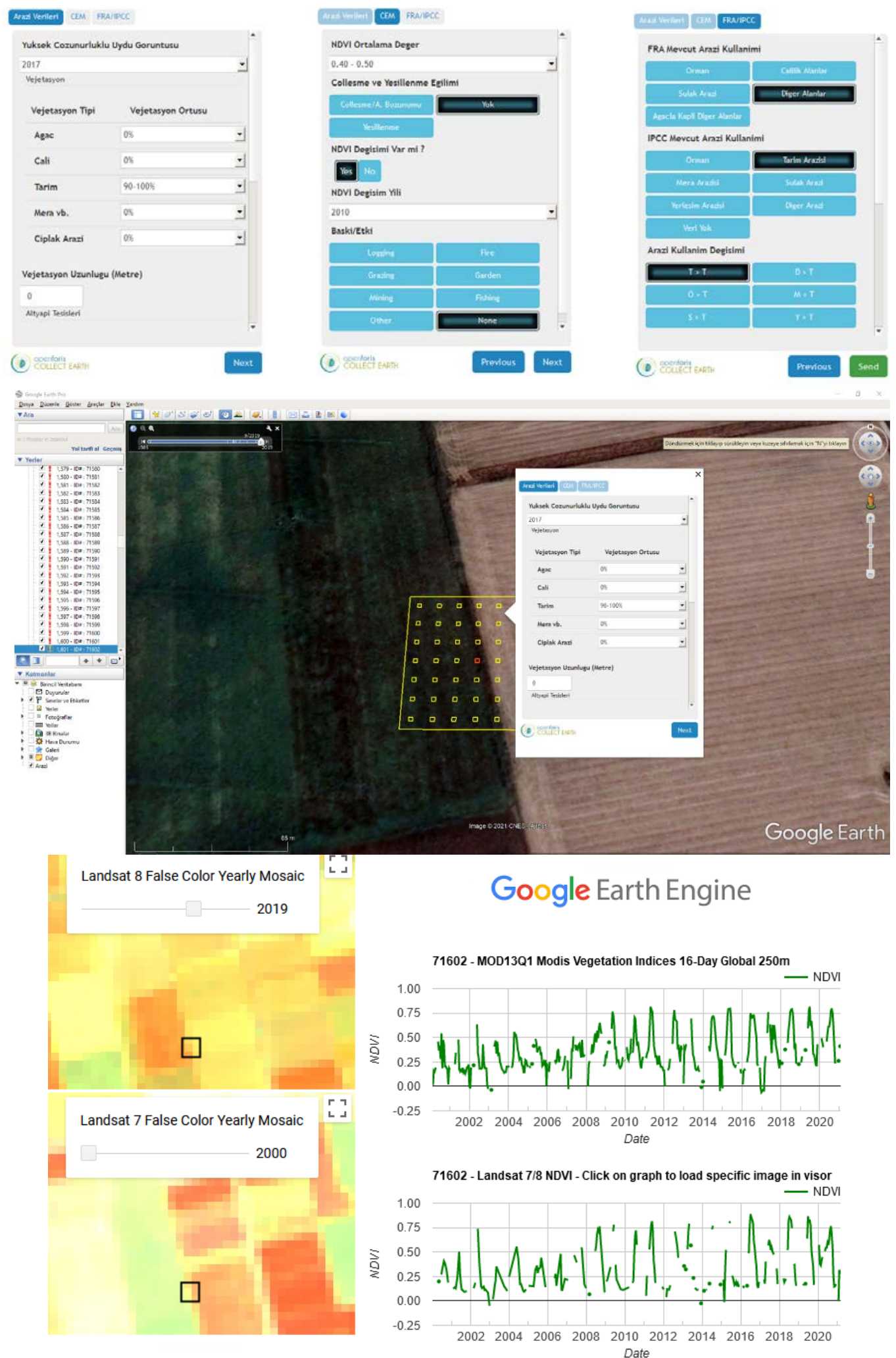

Şekil 5.Collect yazılımı ile hazırlanan kart bölümleri ve Google Earth üzerindeki görünümü, GEE alt yapısı ile hazırlanan ek uydu görüntü verileri (Landsat 7 ve 8 yalancı renkli görüntüler) ve Landsat7/8 ve MODIS NDVI grafik verileri.

Figure 5. The section of identification card prepared in Collect software and the appearance on the Google Earth, additional geodata (Landsat 7 and 8 false colour mosaics, NDVI values obtained from Modis and Landsat) created with the GEE infrastructure used in the interpretation of plots 


\section{Bulgular}

KKH içerisindeki Tuz Gölü, Beyşehir Gölü ve diğer büyük göller dışarıda bırakılarak toplam 49805,32 km² alanda 0,5 ha'lık 8010 plot alanda değerlendirmeler gerçekleştirilmiştir. Sonuçlar Türkiye'nin kurak alanlar sınıflarına (Türkeş, 1999) göre de ayrıca üretilmiştir

\subsection{Arazi Kullanım sinıfları}

KKH'nın IPCC'ye göre, en büyük arazi sınıfını 2.27 milyon ha (\%45.7) ile tarım sınıfı oluşturmaktadır. Büyüklük olarak diğer ve mera arazi sınıfları birbirine yakın sınıflardır. (Çizelge 1). KKH'nın kuraklık sınıfları dağılımları incelendiğinde, havzanın \%54.25'i yarı kurak alanlar sınıfında yer almaktadır. Dolayısı ile en büyük alan sahip olan tarım sınıfının \%25.06'sı yarı kurak sınıfı içerisinde kalmaktadır (Şekil 5).

Arazi örtüsü/kullanımı sınıflandırılması kapsamında, küresel ölçekte orman ve odunsu ağaç/çalı kaynaklarının değerlendirilmesi amaçlı FAO/FRA sınıfları içerisinde orman sınıfı hariç 340118 ha alanda odunsu vejetasyon alanları tespit edilmiştir (Çizelge 2). Orman alanları ile birlikte KKH'nın \%12'si diğer odunsu vejetasyon alanları ile kaplıdır (Şekil 5).

Çizelge 1. KKH'nın arazi kullanım sınıfları (IPCC'ye göre)

Table 1. IPCC Land use classification of KKH

\begin{tabular}{c|ccccccc}
\hline $\begin{array}{c}\text { IPCC Kullanım } \\
\text { SInıf }\end{array}$ & $\begin{array}{c}\text { Orman } \\
\text { alanı }\end{array}$ & $\begin{array}{c}\text { Tarım } \\
\text { alanı }\end{array}$ & $\begin{array}{c}\text { Diğer } \\
\text { alan }\end{array}$ & $\begin{array}{c}\text { Mera } \\
\text { alanı }\end{array}$ & $\begin{array}{c}\text { Sulak } \\
\text { alan }\end{array}$ & $\begin{array}{c}\text { Yerleşim } \\
\text { alanı }\end{array}$ & Toplam \\
\hline Alan (ha) & 258043 & 2279480 & 1080668 & 1039010 & 200838 & 122493 & $\begin{array}{c}\mathbf{4 9 8 0 5 3 2 . 0} \\
\mathbf{0}\end{array}$ \\
\hline
\end{tabular}

Çizelge 2. KKH'nın arazi kullanım sınıfları (FAO/FRA'ye göre)

Table 1. FAO/FRA Land use classification of KKH

\begin{tabular}{c|ccccc}
\hline FAO/FRA sınıfı & Orman & Diğer Odunsu Alanlar & Diğer Alanlar & Sulak Alanlar & Toplam \\
\hline Alan (ha) & 258043 & 340118 & 4181533 & 200838 & $\mathbf{4 9 8 0 5 3 2}$ \\
\hline
\end{tabular}

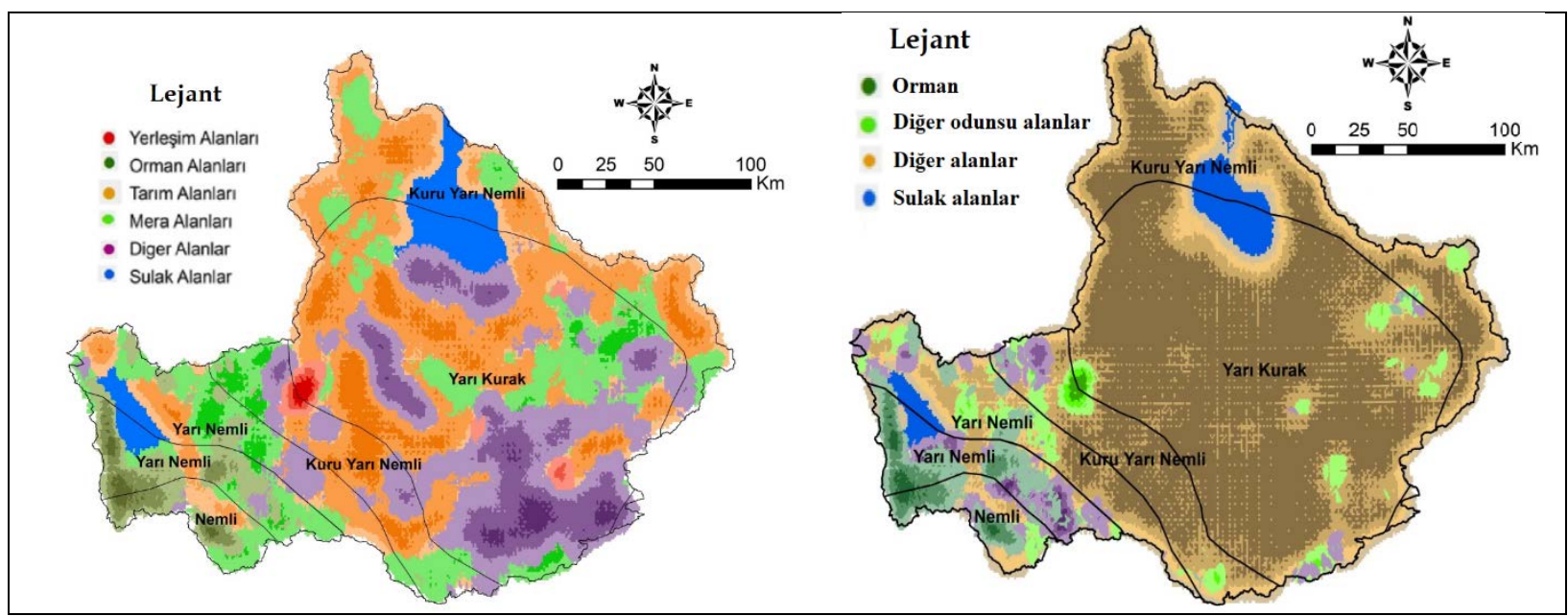

Şekil 5. IPCC Arazi kullanım haritası (Sağ); FAO/FRA arazi kullanım haritası (să̆)

Figure 6. Map of IPCC land use (left), Map of FAO/FRA land use (Right)

\subsection{Arazi bozulumu ve iyileşme eğilim analizi}

KKH' nın NDVI bazlı grafikler ve Google Earth görsel yorumlama sonuçlarına göre Havzası'nda arazi bozulumu/çölleşme alanı10.57 bin ha (\% 0.21), iyileşme/yeşillenme alanı 88.91 bin ha (\%1.78) tespit edilmiştir Çizelge 2). IPCC arazi sınıflarına göre iyileşmenin en çok olduğu sınıf 75.23 bin hektar ile tarım sınıfıdır. Bu sıralamayı 11.81 bin hektar ile orman sınıfı takip etmektedir. Arazi bozulumunun en çok olduğu sınıf ise, 3.1 bin 
hektar ile mera ve diğer alanlar sınıflarıdır. Bu sıralamayı 2.48 bin hektar ile yerleşim sınıfı takip etmektedir (Şekil $6)$.

Çizelge 2. KKH arazi bozulum/iyileşme alanları

Table 2. Land degradation/improvement areas of KKH.

\begin{tabular}{cccccccc}
\hline Eğilim/Arazi kullanım sınıfı & Orman alanı & Tarım alanı & Diğer alan & Mera alanı & $\begin{array}{c}\text { Yerleşim } \\
\text { alanı }\end{array}$ & $\begin{array}{c}\text { Toplam } \\
\text { (ha) }\end{array}$ \\
\hline $\begin{array}{c}\text { İyileşme/yeşillenme } \\
\text { Arazi bozulumu/çölleşme }\end{array}$ & 11814 & 75237 & & 1244 & 622 & $\mathbf{8 8 9 1 6}$ \\
\hline
\end{tabular}

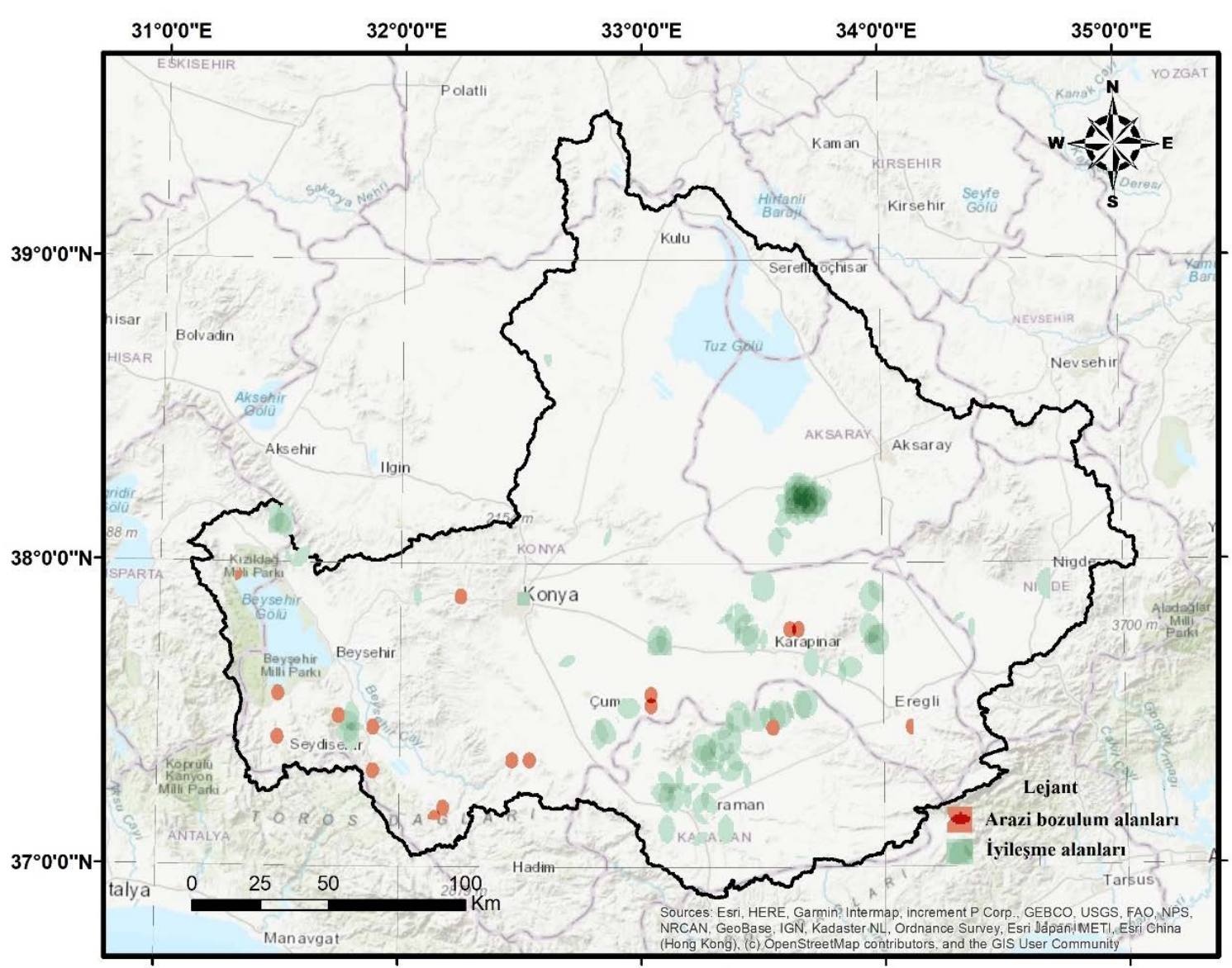

Şekil 6. Arazi bozulum/çölleşme ve İyileşme/yeşillenme alanları nokta yoğunluk haritası

Figure 6. Point density map of Land degradation/desertification and improvement/greening areas

Kuraklık sınıflarına göre ilgili iyileşme ve bozulum alanları incelendiğinde, iyileşme alanı en çok yarı kurak alanlarda (59.69 bin hektar) gerçekleşmiştir. Bu alanı 18.03 bin hektar ile kuru yarı nemli alanlar takip etmektedir. Arazi bozulumu olarak kuraklık sınıfları arasında belirgin bir dağılım olmamakla birlikte, en yüksek bozulum yarı nemli sınıfta gerçekleşmiştir (Çizelge 3).

Çizelge 3. Kuraklık sınıflarına göre arazi bozulum/iyileşme alanları

Table 3. Land degradation/desertification and improvement/greening areas according to dryland category

\begin{tabular}{c|ccccc}
\hline \multicolumn{1}{c}{ Eğilim/Kuraklık sımıfları } & Kuru yarı nemli & Nemli & Yarı kurak & Yarı nemli & Toplam (ha) \\
\hline İyileşme/yeşillenme & 18032 & 2487 & 59692 & 8705 & $\mathbf{8 8 9 1 6}$ \\
Arazi bozulumu/çölleşme & 1865 & 2487 & 2487 & 3731 & $\mathbf{1 0 5 7 0}$ \\
\hline
\end{tabular}


NDVI değişim yıllarının Google Earth ve GEE üzerinden belirlenerek, yıl bazında iyileşme ve bozulum alanlarına göre, özellikle 2009, 2010 ve 2011 yılları en yüksek NDVI bazlı iyileşme eğilimi saptanan yıllar olmuştur. Bununla birlikte iyileşme eğilimi özellikle 2012 yılından 2015 yıllarına kadar bir düşüş eğilimi göstermektedir. Neredeyse 2011 yılana kadar arazi bozulumu saptanamamışken, 2011 yılından sonra eğilim olarak, tahribat alanları gözlenmiştir (Çizelge 4).

Çizelge 4. Yıllara göre arazi bozulum/iyileşme alanları

Table 4. Land degradation/desertification and improvement/greening areas according to years

\begin{tabular}{c|cccccccccccccc} 
Ĕgilim/yıllar & 2002 & 2004 & 2005 & 2006 & 2007 & 2008 & 2009 & 2010 & 2011 & 2012 & 2013 & 2014 & 2015 & Toplam (ha) \\
\hline İyileşme/yeșillenme & 1865 & & 1244 & 1244 & 3732 & 4353 & 21763 & 11192 & 18030 & 6840 & 9948 & 3109 & 5596 & 88916 \\
Arazi bozulumu/çölleşme & & 1244 & 622 & & & & & & 1244 & 622 & 3731 & 1244 & 1865 & 10570
\end{tabular}

\section{Tartışma ve Sonuç}

Bu çalışmada, Konya Kapalı Havzası NDVI bazlı bir arazi bozulumu, iyileşme eğilim analiz sonuçları verilmiştir. Elde edilen sonuçlar, Hazanın iyileşme alanlarının artığına yöneliktir. İyileşme alanlarının arazi sınıfları bazında incelendiğinde, iyileşme alanlarının en çok tarım alanlarında olduğu gözlenmiştir. Elde edilen sonuçlar, sulanmayan tarım alanlarının zamanla sulanmaya geçilmesiyle birlikte vejetasyonun su kullanımı ile birlikte toprağı örtme yüzdesinin artması ya da ikincil ürün gibi faktörler nedeniyle bölgedeki ürün bazlı çeşitliliğinin ve devamlılığı neticesinde oluşmaktadır. TUBİTAK-MAM (2010) da hazırlanan raporda havzada su tüketiminin önemli bir kısmı tarımsal amaçlı kullanıldığı ifade edilmiştir. Yeraltı suyu başta olmak üzere, baraj ve göletlerden alınan suyun yaklaşık \%70'i tarımsal amaçlı kullanıldığı belirtilmiştir. Çalışmada sürütülebilir havza yönetimi vurgusu yapılarak, su kaynaklarının yönetiminin etkin ve yetkin olarak yapılması vurgulanmıştır. Gerçekleştirilen çalışmada elde edilen sonuçlar, tarım alanlarındaki artışın tamamına yakının sudan kaynaklı olduğunu ve bu nedenle, su kaynaklarının yönetimi esaslı politika ve iyi uygulama örneklerine ilişkin planlamaların önemini arttırmaktadır. WWF, 2014 raporunda Türkiye yeraltı su potansiyelinin yaklaşık \%17'sinin KKH içerisinde olduğu belirtilmiştir. Ayrıca raporda, Devlet Su İşleri Bölge müdürlüğünce açılan resmi kuyular haricinde, yaklaşık 67000 yeraltı suyu kuyu sayısından bahsedilmektedir. KKH yıllık su bütçesi yıllık kullanılabilir yeraltı suyu potansiyelinin \%82'si tarımda sulamam amaçlı kullanıldığı da raporda yer almıştır. Bu rakamın su bütçesinin üzerinde olduğu vurgulanmıştır. Yapılan çalışma ile birlikte, tarım alanlarındaki mevcut iyileşme/yeşillenme alanlarının suyun kullanımına yönelik olduğu kesindir. Lakin bu durum bölgedeki tarımsal ürünü destekler nitelikte algılansa da, KKH içerisindeki suyun kullanımı ve su bütçesi noktasında dikkat edilmesi gereken bir husustur. Konya Ovası Projesindeki (KOP) toplan sulanan tarım alanlarının 865059 ha olduğu düşünüldüğünde ve bunun arttırılması yönündeki politikaların olduğu gerçeği, havza içerisindeki suyun kullanımı ve uygulamaları noktasında hassas olunması zorunluluğu getirmektedir. Çizelge 4'te verilen yıllara göre iyileşme trendinin en fazla olduğu yılların başlangıcı olan 2009 yılı ve sonrası, KOP eylem planı (2014-2018) raporu (Kalkınma Bakanlığı, 2014) kapsamında sulanan alanın arttırılması hedefleri ile örtüşmektedir. $\mathrm{Bu}$ çalışma, KOP projesi sonuçlarının bölgedeki tarım alanlarının sulanmasının arttığını ve dolayısı ile vejetasyona bağlı artış ve yeşillenmeyi kanıtlamıştır. Suyun kullanımına yönelik tarım alanlarındaki artışın yeşillenmeden ziyade suya bağlı bir tarım ürünü artışını söylemek mümkündür. Tarım alanlarındaki bu yeşillenme miktarı suya bağımlı bir artış olmakla birlikte, havzadaki ana problemin su bütçesi ve kullanımı olduğu gerçeğini bir kez daha gözler önüne sermektedir. Aynı alanda mevcut ürünün suya bağlı olarak daha fazla olması, gerek bir sezonda ikinci ürün yetiştirerek sağlanan bu vejetasyon artışı, yeşillenme olgusunu doğurmuş olmaktadır. Bu durumun sürdürülebilir olması bölgedeki suyun sürdürülebilir şekliyle kullanılmasına bağlıdır. Bölgedeki aşırı su kullanımı ve yönetim politikaları sorununun (WWF,2016; Ökten, 2011), çözümüne yönelik modern sulama sistemlerine (yağmurlama, damlama, pivot sistemler vb.) geçişin ve bunların mutlak takibi ve sağlanmasına yönelik politikalar olduğu bir gerçektir.

Bozyiğit, 2014' te yaptığı çalışmada iklim nedeniyle KKH sınırları içerisinde yağışın azlığı ve toprak üzerindeki bitki örtüsünün bulunmadığı ya da kaldırıldığı alanlarda rüzgar erozyonu etkili olduğunu belirtmiştir. Bu bağlamda tarım alanlarındaki suyun kullanımına yönelik yeşillenme alanlarında bir anlamda rüzgar erozyonuna engel olunmuştur. Lakin genel durum suyun kullanımı olduğu için, bölgedeki rüzgar erozyonunun şiddeti de suya ve kullanıma yönelik vejetasyon örtüsünün varlığı ile alakalıdır. Söz konusu tarım alanları olduğunda ise, hasat zamanından sonra toprağın boş kalması durumunda suyun rüzgar erozyonunu engellemek maksatlı kullanımı da bölgedeki diğer bir önemli konu haline gelmektedir.

Orman alanı içerisindeki 11814 ha alanda yeşillenme /iyileşme görülmesi bu alanlarda arazi bozulumunun hiç yaşanmaması bölge için zaten az bulunan orman varlığı, iklim koşulları düşünüldüğünde büyük bir kazanımdır. Buradaki yeşillenmenin en büyük nedeni T.C. Tarım ve Orman Bakanlığı Orman Genel Müdürlüğünce yapılan başarılı çalışmaları (Orman ve Su İşleri Bakanlığı, 2014; Yıldız ve ark., 2018)) olduğu görsel olarak tespit edilmiştir. KKH içerisindeki mera, yerleşim ve diğer arazi kullanım sınıflarında arazi bozulumu fazla olarak tespit edilmiştir. 
Yerleşim alanlarına yönelik yapılaşmanın artması neticesinde karşılaşılan arazi bozulmaları genel olarak inşaat sektörüne yönelik tespitlerdir. Mera ve diğer arazi sınıflarına yönelik arazi bozulumu ise mevcut iklim ve coğrafi koşulların doğal bir sonucu olarak yorumlanmalıdır. Orhan ve Ekercin, 2015 yılında yaptığı çalışmada arazi yüzey sıcaklığının 1984-2011 yılları arasında yaklaşık $2^{\circ} \mathrm{C}$ arttığını göstermiş, diğer iklim verisi analizleri ile birlikte havzanın giderek kuraklaştığını belirtmişlerdir. Yılmaz, 2017 yılında Çoklu-Uydu Yağış Analizi (TMPA) uydu kaynaklı yağış verilerini kullanarak 1998-2015 yılları arasındaki süreçte yaptığı çalışmada da, kuraklık bulgularına rastlamıştır. Gerçekleştirilen çalışma sonucunda, kuraklık durumu yapılan çalışmalarla birlikte orman alanları gibi doğal bir arazi örtü sınıfını etkilememiş gözükse de, diğer doğal sınıf olan mera ve diğer alanlar sınıfını olumsuz etkilediği tespit edilmiştir.

Bu çalışmada kullanılan Collect Earth yazılımı özellikle küresel, ulusal ve bölgesel büyük ölçekli alanlarda arazi izleme ve değerlendirme yöntemi olarak kullanılabileceğini kanıtlamıştır. Özellikle günümüz büyük alanlarda arazi çalışmalarında farklı nedenlerden dolayı veriye ulaşımın kolay olmadığı düşünüldüğünde, yüksek çözünürlüklü görüntü ve grafik verileri üzerinden veri toplayabilme kabiliyeti olması CE'nin gelecekte birçok çalışmada kullanılabileceğini kanıtlamaktadır. Yöntemin diğer bir başarısı uzun yıllar arazi izleme ve değerlendirebilme özelliğinin olmasıdır. Sentinel vb. tarzı ücretsiz kullanıma ve daha yüksek çözünürlüklü verilerin kullanımın yaygınlaşması durumunda, CE yönteminin etkinliği de artacaktır. Dink ve ark., 2020 yılında Çin in büyük bir eyaletinden yaptığ yapmıştır. Benzer olarak CE yardımı ile, GEE üzerinden zaman serileri bazında elde edilen ekolojik verilere (yağış, toprak nemi, Evapotranspirasyon, sıcaklık vb.) ilişkin bilgilerle birlikte yorumlanması, KKH ve diğer havzaların arazi izleme ve değerlendirme çalışmalarına ekosistem bütünü ve sürdürülebilirlik çerçevesinde oldukça yüksek bir katma değer sunacaktır. KKH' nın gelecekte GEE üzerinden diğer ekolojik faktörlerde alınarak arazi örtü/kullanım sınıflarının izlenmesi havza içerisindeki tüm projelerin ve devam eden sürecin takibi açısından önemlidir.

\section{Teşekkür}

Bartın Üniversitesi Bilimsel Araştırma Projeleri Komisyonu tarafından desteklenmiştir (Proje No: 2017-FEN-B002). Projeye olan katkılarından dolayı, Orman Yük. Müh. Talha Berk Arıkan, Orman Yük. Müh. Saffet YILDIZ, Tarım ve Orman Bakanlığı, Çölleşme ve Erozyonla Mücadele Genel Müdürlüğü’ne teşekkür ederim.

\section{Kaynaklar}

Ateșoğlu, A., Arikan, T. B., Yildiz, S., 2019. Assessment of forest, grassland, and agricultural land use in Konya basin. Bartın Orman Fakültesi Dergisi, 21(3), 821-832.

Bahre, C. J., 1991. A legacy of change: historic human impact on vegetation in the Arizona borderlands. University of Arizona Press, Tucson, Arizona.

Bai, Z.G., De Jong, R., Van Lynden, G.W.J., 2010. An update of GLADA—global assessment of land degradation and improvement. ISRIC report 2010/08. ISRIC—world soil information. p. 58., Rome/Wageningen

Bai, Z.G., Dent, D.L., Olsson, L., Schaepman, M.E., 2008. Global assessment of land degradation and improvement 1: identification by remote sensing. Report 2008/01. FAO/ISRIC. p 51+Appendices,.

Bannari, A., Morin, D., Bonn, F., Huete, A.R., 1995. A review of vegetation indices, Remote Sensing Reviews, 13:1-2, 95-120, doi:: 10.1080/02757259509532298

Bey, A., Sánchez-Paus Díaz, A., Maniatis, D., Marchi, G., Mollicone, D., Ricci, S., ... \& Miceli, G., 2016. Collect earth: Land use and land cover assessment through augmented visual interpretation. Remote Sensing, 8(10), 807.

Ding, Q., Wang, L., Fu, M. et al., 2020. An integrated system for rapid assessment of ecological quality based on remote sensing data. Environ Sci Pollut Res 27, 32779-32795. https://doi.org/10.1007/s11356-020-09424-6

FAO/FRA, 2015. Terms and Definitions. Web site. http://www.fao.org/docrep/017/ap862e/ap862e00.pdf (Erişim tarihi: Eylül 20219).

Gorelick, N., Hancher, M., Dixon, M., Ilyushchenko, S., Thau, D., Moore, R., 2017. Google Earth Engine: Planetary-scale geospatial analysis for everyone. Remote sensing of Environment, 202, 18-27.

Guo, Y., Wang, C., Lei, S., Yang, J., Zhao, Y. A. 2020. Framework of Spatio-Temporal Fusion Algorithm Selection for Landsat NDVI Time Series Construction. ISPRS Int. J. Geo-Inf. 9, 665. https://doi.org/10.3390/ijgi9110665

IPCC, 2003. The Inter-Governmental Panel on Climate Change, Good Practice Guidance for Land Use, Land-Use Change and Forestry. Web site. https://www.ipcc-nggip.iges.or.jp/public/gpglulucf/gpglulucf_files/GPG_LULUCF_FULL.pdf (Erişim tarihi: Kasım 2020).

Islam, M., Saiful, M., Asraf, U., Mallik, A.H., 2021. Assessing the Dynamics of Land Cover and Shoreline Changes of Nijhum Dwip (Island) of Bangladesh Using Remote Sensing and GIS Techniques. Reg. Stud. Mar. Sci. 41, 101578.

Ivanova, Y., Kovalev, A., Soukhovolsky, V. 2021. Modeling the Radial Stem Growth of the Pine (Pinus sylvestris L.) Forests Using the Satellite-Derived NDVI and LST (MODIS/AQUA) Data. Atmosphere 2. 12, 12. https://doi.org/10.3390/atmos12010012

Jones, H.G., Vaughan, R.A., 2010. Remote Sensing of Vegetation: Principles, Techniques and Applications Oxford University Press. 365 s, NY. 
Jong, R., De Bruin, S., De Wit, A., Schaepman, M. E., Dent, D. L. 2011. Analysis of monotonic greening and browning trends from global NDVI time-series, Remote Sensing of Environment, 115, 692-702.

Kalkınma Bakanlığı, 2014. Konya Ovası (KOP) Eylem planı (2014-2018), T.C. Kalkınma Bakanlığı, Konya ovası projesi bölge kalkınma idaresi başkanlığı. 130 s, Ankara.

Khadka, A., Dhungana, M., Khanal, S., Kharal, D. K., 2020. Forest and other land cover assessment in Nepal using Collect Earth. Banko Janakari, 30(1), 3-11.

Liping, C., Yujun, S., Saeed, S., 2018. Monitoring and predicting land use and land cover changes using remote sensing and GIS techniques-A case study of a hilly area, Jiangle, China. PLoS ONE , 13, e0200493.

Lu, L., Kuenzer, C., Wang, C., Guo, H., Li Q., 2015 Evaluation of three MODIS-derived vegetation index time series for dryland vegetation dynamics monitoring. Remote Sensing, 7 (6) (2015), pp. 7597-7614.

Martin-Ortega, P., Garcia-Montero, L., Pascual, C., Garcia-Robredo, F., Picard, N., Bastin, J. F., Sibelet, N., 2017. Global Drylands Assessment using Collect Earth tools and opportunities. Forêt méditerranéenne. 14 rue Louis Astouin, 13002 MARSEILLE, France.

Ökten, S., 2011. Konya havzasında su yönetimi politikalarının yolaçtığı çevre sorunları ve genel çözüme yönelik çalışmalar. Süleyman Demirel Üniversitesi , Vizyoner Dergisi , 3 (5) 124-147.

Orman ve Su İşleri Bakanlığı, 2014. Konya kapalı havzası, karaman ili ayrancı ilçesi başlamışl1-kocadere mikro havzası, entegre mikro havza projesi, Orman ve Su Işleri Bakanlığı, Çölleşme ve Eraozyonla Mücadele Genel Müdürlüğü, 40 s, Ankara.

Saah, D., Johnson, G., Ashmall, B., Tondapu, G., Tenneson, K., Patterson, M., Chishtie, F., 2019. Collect Earth: An online tool for systematic reference data collection in land cover and use applications. Environmental Modelling \& Software, 118, 166-171.

Sluiter, R., 2005. Mediterranean land cover change - modelling and monitoring natural vegetation using GIS and remote sensing. Ph.D Thesis, Utrecht University, 147 pp, Utrecht.

Sobrino, J., Julien, Y., 2011. Global trends in NDVI-derived parameters obtained from GIMMS data Int. J. Remote Sens., 32, pp. 4267-4279.

TUBITAK-MAM, 2010. Havza Koruma Eylem Planlarının Hazırlanması Projesi, Konya Kapalı Havzası Nihai Raporu, (Proje yöneticisi: Dr. Selma AYAZ; Proje Kodu: 5098115), 473 s, Kocaeli.

Türkeş, M., 1999. Vulnerability of Turkey to desertification with respect to precipitation and aridity conditions. Turkish Journal of Engineering and Environmental Sciences 23, 363-380.

Tzamtzis, I., Federici, S., Hanle, L., 2019. A Methodological Approach for a Consistent and Accurate Land Representation Using the FAO Open Foris Collect Earth Tool for GHG Inventories. Carbon Management, 10(4), 437-450.

URL 1. https://atlanticfactorial.com/2020/02/02/what-are-the-important-things-you-need-to-know-about-ndvi/ (Erişim tarihi: Eylül 2020).

Veron, S.R., Paruelo, J.M., Oesterheld, M., 2006. Assessing desertification. Journal of Arid Environments, 66, 751-763.

Wallace J.F., Campbell N., 1990. Analysis of Remotely Sensed Data. In: Hobbs R.J., Mooney H.A. (eds) Remote Sensing of Biosphere Functioning. Ecological Studies (Analysis and Synthesis), vol 79. Springer, New York, NY. https://doi.org/10.1007/978-1-4612-3302-2_14

Wessels, K. J., Prince, S. D., Malherbe, J., Small, J., Frost, P. E., \& VanZyl, D., 2007. Can human-induced land degradation be distinguished from the effects of rainfall variability? A case study in South Africa. Journal of Arid Environments, 68, $271-297$.

Wessels, K.J., Van Den Bergh, F., Scholes, R.J., 2012. Limits to detectability of land degradation by trend analysis of vegetation index data Remote Sensing of Environment, 125, pp. 10-22 http://dx.doi.org/10.1016/j.rse.2012.06.022

WWF, 2014. Konya'da suyun bugünü raporu. Hazırlayanlar: Mustafa Özgür Berke, Buket Bahar Dıvrak, Hatice Dinç Sarısoy. WWF-Türkiye, Ofset yayınevi, 67 s, Ankara.

Yagci, A.L., Deng, M., Di, L., Han, W., Peng, C., 2011. Vegetation index based technique for global agricultural drought monitoring 2011 5th International Conference on Recent Advances in Space Technologies (RAST), pp. 137-141, 09-11 Temmuz, Istanbul.

Yengoh, G.T., Dent, D., Olsson, L., Tengberg, A.E., Tucker, C.J. 2015. Use of the Normalized Difference Vegetation Index (NDVI) to assess land degradation at multiple scales springer briefs in environmental science. Available from: http://link.springer.com/book/10.1007\%2F978-3-319-24112-8 (Erişim tarihi: Şubat 2018).

Yıldız, O, Çetin B., Sargıncı M., vd., 2018. İç Anadolu'da Ağaçlandırma çalışmaları, Journal of Forestry Vol.14, Issue.1, p. 1-20. http://dergipark.gov.tr/journal/256/workflow/active

Zhao, H., Li, Y., Chen, X., Wang, H., Yao, N., Liu F., 2020. Monitoring monthly soil moisture conditions in China with temperature vegetation dryness indexes based on an enhanced vegetation index and normalized difference vegetation index Theoretical and Applied Meteorology, doi: 10.1007/s00704-020-03422-x

Zhu, X.; Xiao, G.; Zhang, D.; Guo, L. 2021. Mapping abandoned farmland in China using time series MODIS NDVI. Sci. Total Environ. 755, 14265. 